\title{
The Influence of Climate Factor on the Yield of Winter Wheat in Germany based on LINTUL 2 Model
}

\author{
Zhe LIU \\ Shaanxi Provincial Land Engineering Construction Group \\ Xi'an 710075, China \\ e-mail: Liuzhe168@126.com
}

\author{
Ying HOU \\ Shaanxi Provincial Land Engineering Construction Group \\ Xi'an 710075, China \\ Rheinische Friedrich-Wilhelms-University Bonn \\ Bonn 53113, Germany \\ e-mail: houying.183@163.com
}

\begin{abstract}
The study, which was conducted in Klein-Altendorf, Nordrhein-Westfalen in Germany, simulated the effect of temperature and solar radiation on the yield of winter wheat from 1991 to 2004 by using LINTUL 2 model. The parameters of temperature and radiation were modified to check the sensitivity of the model with regard to the two variables. Furthermore, it has been discussed how to maintain the original yield under a condition with variable radiation and temperature by changing species with different temperature sum and light use efficiency. The results showed that: under the same radiation value, the temperature increment was linearly negatively correlated with crop yield. The yield decreased with increasing temperature. Under the same temperature, the correlation between solar radiation and crop yield was positive linear. The yield increased with increasing radiation. The effect of radiation factor on crop yield was more sensitive than the effect of temperature. In worse conditions with increased temperature or decreased radiation, man can keep the original yield by changing the cultivars with different temperature sum and light use efficiency (LUE).
\end{abstract}

Keywords- LINTUL 2 model; nordrhein-westfalen germany; climate change; original yield; temperature; radiation

\section{INTRODUCTION}

As the main indicator for global change, climate warming has had significant impacts on human life, including agricultural production for human consumption. Climate change has a critical influence on crop phenology and yield. Some studies indicated that from 1901 to 2000 the global average temperature increased about $0.6^{\circ} \mathrm{C}\left(0.4-0.8^{\circ} \mathrm{C}\right)$ or from 1906 to 2005 about $0.74^{\circ} \mathrm{C}\left(0.56-0.92^{\circ} \mathrm{C}\right)$, and there is a projected further increase by $1.8-4.0^{\circ} \mathrm{C}$ at the end of this century[1-3]. Solar radiation can provide energy for biomass accumulation so that people make an effort to use solar radiation to enhance biomass as much as possible. Under certain conditions, external temperature can also affect photosynthesis greatly[4-6]. Climate change has a crucial influence on crops because growth and development are affected by sunlight, temperature, and water. The effect of climate change on crop production depends on the interaction of various climatic factors and agricultural management parameters. However, the climate change, especially the changes of temperature and radiation are not foreseeable in the near future. Hence, to predict the influence of climate change on crop yield in the near future, it is necessary to simulate the relationship with quantitative model[7-8]. Studies on climate impacts and adaptation strategies of wheat production are increasingly becoming major areas of scientific concern for the reason that the effects of meteorological factor on wheat was greater than other crops due to the longer growth period of wheat [9-10]. However, climate change impacts on crop yield are different in various areas: in some regions it increases, while in others it decreases, which is concerned with the latitude of the area and irrigation application. Nicholls found that the yield of wheat increased about $30-50 \%$ in Australia due to global warming from 1952 to $1992[11]$. You et al. focused on the effect of climate change on wheat yield in recent 20 years in China and pointed out the yield of wheat decreased about $4.5 \%$ from 1979 to 2000 since temperature increased[12]. Lobell et al. indicated since 1980, the global warming caused a $2.5 \%$ decrease of wheat yield globally. In conclusion, the effect of climate change on crop growth and yield is still debatable. More details should be considered[13].

Advancing wheat productivity of Klein-Altendorf will play an important role in ensuring German and global food security. However, this will be a big challenge under the future climate change. In the growth and development stages of wheat, climate factors such as temperature, radiation play a key role. A certain temperature sum is needed in each stage of wheat. For winter wheat, there is a dormancy stage which is influenced by temperature and solar radiation[14-15]. Hence, a better understanding of the regional temperature and radiation, thinking about some adaptive strategies are important for the sustainable development of local agriculture. Correlation analysis of historical climate data and crop yield records have been successfully and widely used in establishing relationships between crop production and climate change. Some advanced statistical methods and regression analysis were used to separate the contributions of climate factors, crop variety, management, etc. on yield variations leading to a better understanding of the effects of historical climate change[16]. Along these lines, we performed a simple correlation analysis to study the relationship between crop yield and the key climate factors in Klein-Altendorf from 1991 to 2004. A LINTUL 2 model 
was built to discuss the relationship between changes of temperature and radiation and winter wheat yield and finally to provide the reference value for wheat potential yield and cultivation management.

\section{MATERIALS AND MethODS}

\section{A. Study Area and Materials}

This experiment was conducted in Klein-Altendorf, Nordrhein-Westfalen in Germany $\left(6^{\circ} 59^{\prime} 32^{\prime \prime} \mathrm{E}, 50^{\circ} 37^{\prime} 51^{\prime \prime} \mathrm{N}\right)$. The Klein-Altendorf lies in one of the most important fruitgrowing areas of Germany between Meckenheim and Rheinbach in the southern Niederrhein bay on the main terrace of the Rhine. The soil is loamy silt and rich in nutrition. The average annual precipitation is about $603 \mathrm{~mm}$. The average annual temperature is $9.4{ }^{\circ} \mathrm{C}$ and the vegetation period is 165 - 170 days (1950-2014). The cultivated winter wheat is Triticum aestivvm $\mathrm{L}$. and cultivated on the beginning of November and harvested on July.

\section{B. Sampling}

The data about emergency day of year (DOY), temperature, radiation, light use efficiency(LUE) and temperature sum for anthesis, temperature sum for maturity of winter wheat, leaf area index (LAI) were provided by Rheinische Friedrich-Wilhelms-University Bonn in Germany, which were collected from 1991 to 2014.

\section{LINTUL-Model Overview}

The LINTUL model firstly deviated from the De Wit Shool photosynthesis based modes and has been used in numerous climate change studies[17]. This model is base on the original LINTUL version by Spitters (1987) and the subsequent version by Spitters and Schapendonk (1990). The model can be considered as a functional model to use daily solar radiation as the amount of energy, which is available for photosynthesis. This energy intercepted by the crop is approximated using information that is feedback from the plant leaf area index to calculate approximate biomass production per unit of radiation intercepted[18]. The LINTUL model therefore uses a linear relationship between the production of biomass and amount of solar radiation that the crop's canopy intercepts[19]. In this project, we used the following model (Figure 1) in the modeling framework misplace with the LINTUL-solution.

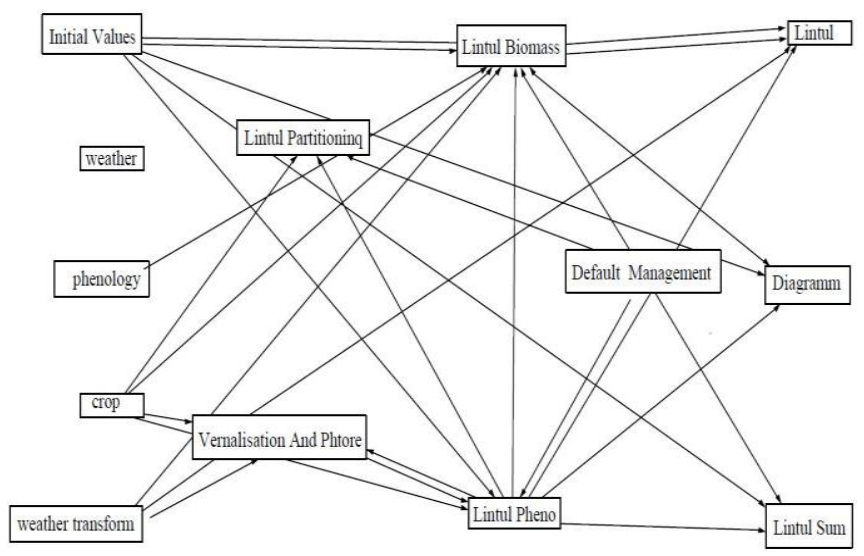

Figure 1. LINTUL-Model overview.

\section{Statistical Analysis}

At the beginning, the radiation factor 1 and temperature increment 0 represented the average annual radiation and temperature respectively. Radiation can change from 0-2 (eg1.2 here means $20 \%$ increase). The temperature increment changes from -5 to $5^{\circ} \mathrm{C}$. The original light use efficiency (LUE) of the winter wheat used in this experiment was 3 and temperature sum for maturity was $1350^{\circ} \mathrm{C}$.

\section{RESULTS}

\section{A. Relative Yields under Different Temperature Increment}

Many valuable conclusions about effects of temperature on wheat growth and yield were reported through different research methods[20-21]. From the LINTUL 2 model, it simulated the yield of winter wheat under different solar radiation and temperature. To investigate the sensitivities of wheat yield to temperatures and solar radiations, we ran the model with observed climate data from 1991 to 2004. The model showed clearly that with original radiation factor $(\mathrm{r}=1)$, the yield decreased with the increased temperature and the correlation was negative linear $(y=-29.256 x+865.51$, $\mathrm{R}^{2}=0.9953$ ) (Figure 2) .

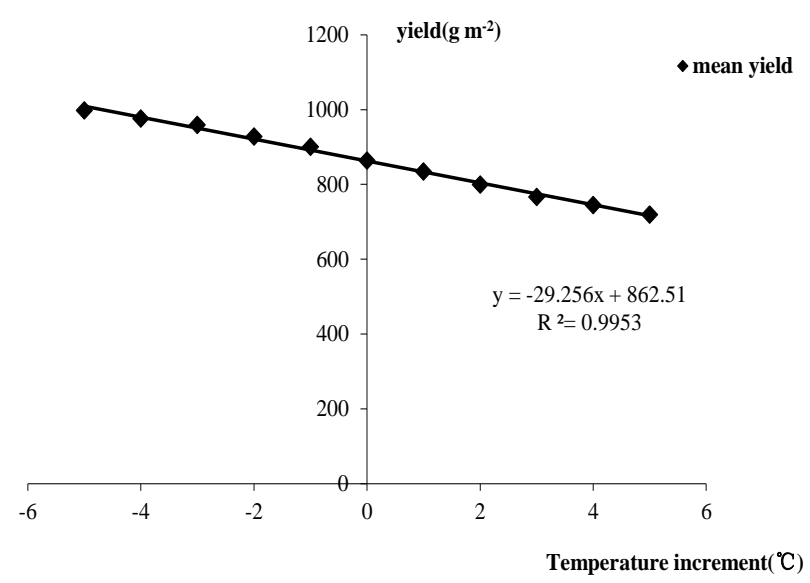

Figure 2. Mean yields under different $\mathrm{T}$ increments $(\mathrm{RF}=1)$. 


\section{B. Relative Yields under Different Radiation Factors}

Through the simulated changing of radiation, it is proved that the influence of solar radiation on the yield of winter wheat was significant. The results showed with a stable temperature but an increased radiation, mean yield also increased, and there was a significant positive correlation between mean yield and radiation increment $(y=954.1 \mathrm{x}$ 89.588, R ${ }^{2}=1$ ) (Figure 3).

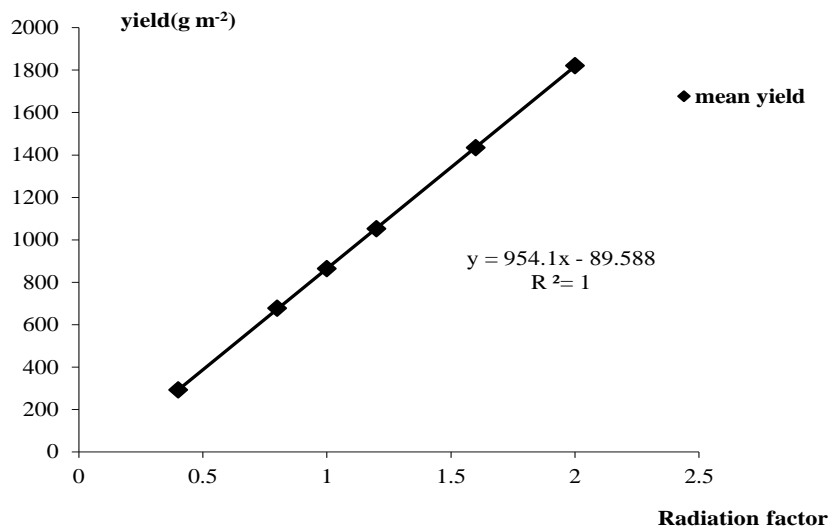

Figure 3. Mean yields under different radiation factors $\left(\mathrm{T}\right.$ increment $\left.=0^{\circ} \mathrm{C}\right)$.

\section{Mean Yield under Different Temperatures and Different Radiation Factors}

The changes of mean yield under interaction of temperature and radiation showed the sensitivity of the yield with regard to these two variables (Figure 4). For example, if $\mathrm{r}=1.2$, temperature increment $=1$, the yield might be much higher than original yield. If $\mathrm{r}=0.8$, temperature increment $=-2$, the yield was much lower. The results indicated that the effect of radiation on yield was more sensitive than the effect of temperature.

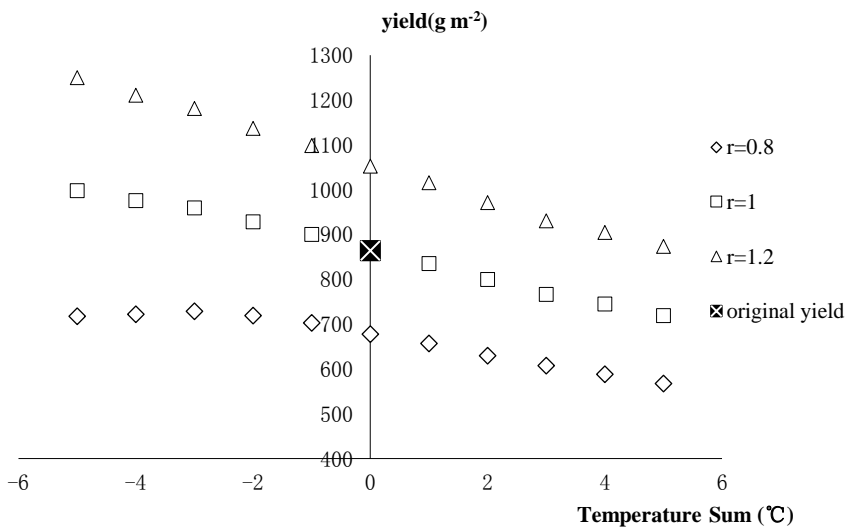

Figure 4. Mean yield under different temperatures and different radiation factors.

\section{DISCUSSION}

\section{A. To Maintain the Original Yield When the Temperature Increases}

For winter wheat there is a stop-growth phase called dormancy stage. The period of this stage is mainly influenced by outside temperature. In the same way, the crop phenology might be limited by global warming. On the other hand, radiation is the sole energy source for crop growth, which also as a main limiting factor for crop yield[22]. The results through the simulated model showed that both an increase of radiation and a decrease of temperature caused an increase of simulated yield. And the effect of radiation change on yield was more sensitive.

Actually in order to maintain the original yield under different weather conditions, we can just change the crop characters by using different crop species with different temperature sum and LUE. To accelerate understanding of climate impacts, among other things, we need to understand their relative contributions of cultivars, agronomic management and climate change to crop yields change. There are two common conditions. In near future, the temperature might be increase but solar radiation is still stable. To maintain the original yield, we ran the model with parameter radiation $=1$ and temperature increment $=1$, and it showed the original yield $\left(863 \mathrm{~g} \mathrm{~m}^{-2}\right)$ could be maintained by increasing temperature sum to a level of 1530 (Figure 5).

If the radiation factor was simulated to 1 and change the temperature increment to 2 , that means the temperature increment level was higher (Figure 6). Then even temperature sum was up to the peak level of 1600 in the model, the original yield could still not be kept $\left(863 \mathrm{~g} \mathrm{~m}^{-2}\right)$.

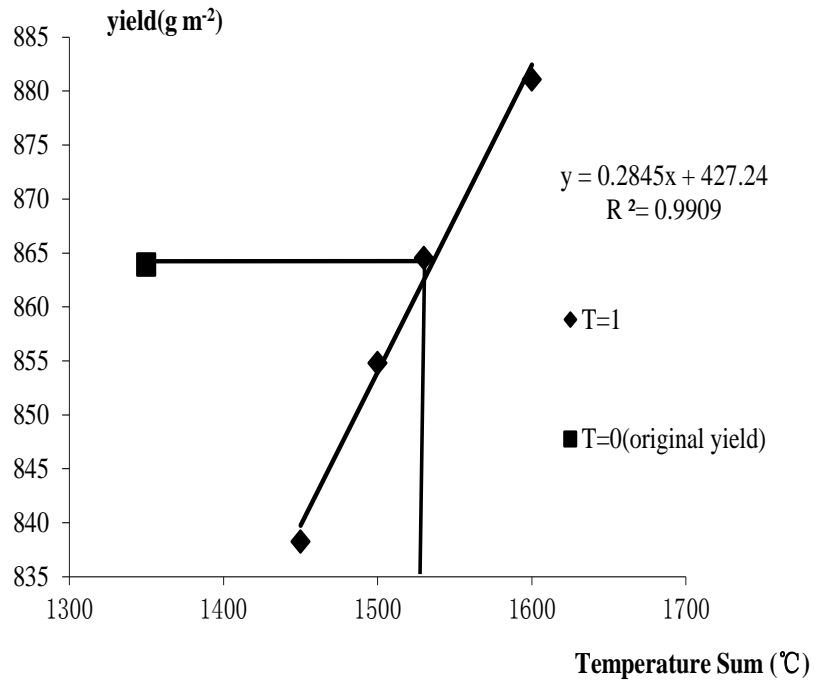

Figure 5. Mean yield related to different $\mathrm{T}$ sums $(\mathrm{T}$ increment=1). 


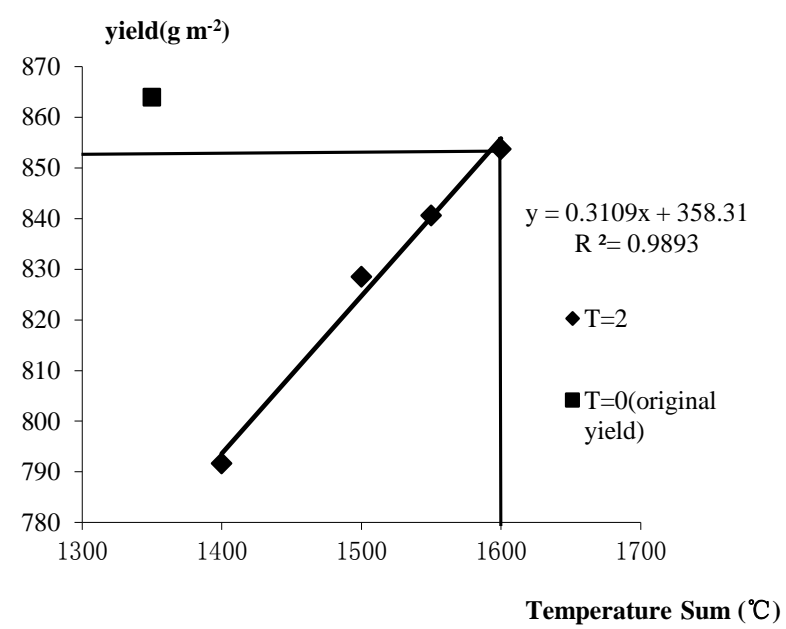

Figure 6. Mean yield related to different $\mathrm{T}$ sums ( $\mathrm{T}$ increment=2).

\section{B. To Maintain the Original Yield When the Radiation Decreases}

The other possibility is that in recent five years, temperature might be relatively stable, but the radiation might be changeable due to the fog. A case of climate with an $20 \%$ decrease of radiation was simulated (temperature increment $=0$, radiation factor 0.8 ) (Figure 7). The results pointed out an increase LUE to a level of 3.75 could maintain the original yield $\left(863 \mathrm{~g} \mathrm{~m}^{-2}\right)$.

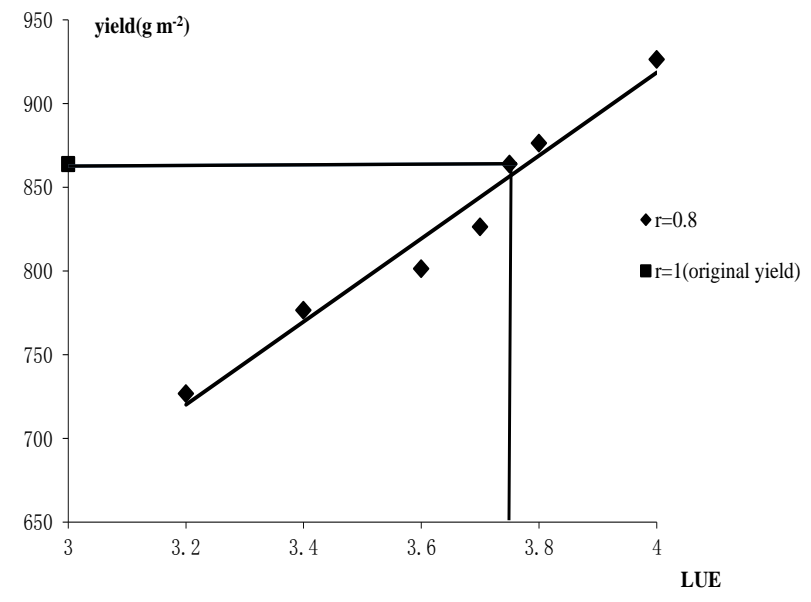

Figure 7.Mean yield related to LUE(T increment $=0$ ).

\section{CONCLUSIONS}

From the first two results of our model we've known that, increasing temperature leads to lower yields, and the relationship seems to be linear $\left(\mathrm{y}=-29.256 \mathrm{x}+862.51, \mathrm{R}^{2}=\right.$ 0.9953 ), and also increasing radiation leads to higher yields, the relationship seems also to be linear $(y=954.1 \mathrm{x}-89.588$, $\mathrm{R}^{2}=1$ ). In addition, from the third result we can conclude that, the effect of radiation factor was more sensitive than the effect of temperature. And finally we can conclude that, to maintain the original yield in worse conditions, may can change the cultivars with different T sum and LUE. However in our model we mainly focused on two main factors which including temperature and radiation. Actually an increased radiation can lead to a higher yield only if the adequate water supply is assumed. The model doesn't consider the water supply of the canopy. So to get the exact results of the yield from the model, more influenced factors and conditions are needed to be evaluated and furthermore to improve this model.

\section{ACKNOWLEDGMENT}

This work was supported by the Shaanxi Focus on science and technology innovation team (no. 2016KCT-23) and the Key Laboratory of Degraded and Unused Land Consolidation Engineering, the Ministry of Land and Resources of China. The authors gratefully acknowledge researchers at the Rheinische Friedrich-Wilhelms-University Bonn, their partners and supervisor Thomas Gaiser for their help with the experiments.

\section{REFERENCES}

[1] Solomon S, Qin D, Manning M, et al. IPCC Fourth Assessment Report:Climate Change, 2007(AR4).http://www.ipcc.ch/publications_ and_data/publications_and_data_reports.shtml.

[2] Houghton J T, Ding Y, Griggs D J, et al. IPCC Third Assessment Report: Climate Change, 2001(TAR).http://www.ipcc.ch/ipccreports /tar/vol4/index.htm.

[3] J. R. Porter, M. A. Semenov. Crop responses to climatic variation. Philosophical Transactions of the Royal Society, vol. 360 (1463), pp. 2021-2035, 2005.

[4] W. Li, X. L. Sui,Z. X. Zhang. Effects of temperature regime on lowlight tolerance of Cucumis sativus seedling leaves in their photosynthesis. Chinese Journal of Applied Ecology, vol. 19 (12), pp. 2643-2650, 2008.

[5] Z. Q. Yang, J. F. Dai, W. H. Luo, et al. Effects of stem numbers perground area on the quality of standard cut Chrysanthemum morifolium in greenhouse: Simulation model. Chinese Journal of Applied Ecology, vol. 19 (3), pp. 575-582, 2008.

[6] H. B. Jiang, X. L. Tian, S. L. Dong, et al. Effects of temperature and light intensity on the growth and biochemical composition of Sargassum thunbergii. Chinese Journal of Applied Ecology, vol. 20 (1), pp. 185-189, 2009.

[7] J. E. Olesen, M. Bindi. Consequences of climate change for European agricultural productivity, land use and policy. European Journal Agronomy, vol. 16 (4), pp. 239-262, 2002.

[8] F. L. Tao, M. Yokozawa, Y. L. Xu, et al. Climate changes and trends in phenology and yields of field crops in China 1981-2000. Agricultural and Forest Meteorology, vol. 138 (1/4), pp. 82-92, 2006.

[9] A. J. Challinor, T.R. Wheeler. Crop yield reduction in the tropics under climate change: processes and uncertainties. Agr. Forest. Meteorol. vol. 148, pp. 343-356, 2008

[10] H. S. Yu, D. L. Wei. Impacts of climate on wheat yield and there changes in Henan province. J. Nat. Resour. Chin. vol. 15, pp. 149-154, 2000 .

[11] N. Nicholls. Increased australian wheat yield due to recent climate trends. Nature, vol. 387 (6632), pp. 484-485, 1997.

[12] L. Z. You, M. W. Rosegrant, S. Wood, et al. Impact of growing season temperature on wheat productivity in China. Agricultural and Forest Meteorology, vol. 149 (6/7), pp. 1009-1014, 2009.

[13] D. B. Lobell, W. Schlenker, J. Costa-Roberts. Climate trends and global crop production since 1980. Science, vol. 333 (6042), pp. 616620, 2011. 
[14] D. B. Lobell, M. B. Burke. Climate Change and Food Security: Adapting Agriculture to a Warmer World. Netherlands: Springer, 2010.

[15] D. P. Xiao, F. L. Tao. Impact of climate change in 1981-2009 on winter wheat phenology in the North China Plain. Chinese Journal of Eco-Agriculture, vol. 20 (11), pp. 1539-1545, 2012.

[16] A. Bhatia, H. Pathak, P. K. Aggarwal. "Trade-off between productivity enhancement and global warming potential of rice and wheat in India". Nutrient Cycling in Agroecosystems, vol. 86, pp. 413-424, 2010.

[17] B. A. M. Bouman, H. V. Keulen, H. H. V. Laar, et al. The 'School of de Wit' crop growth simulation models: A pedigree and historical overview. Agricultural Systems, vol. 52 (2), pp. 171-198, 1996.

[18] B. Basso, C. Fiorentino, D. Cammarano, et al. Analysis of rainfall distribution on spatial and temporal patterns of wheat yield in
Mediterranean environment. European Journal of Agronomy, vol. 41 (2012), pp. 52- 65, 2012.

[19] E. J. Allen, R. K. Scott. An analysis of growth of the potato crop. Journal of Agricultural Science, vol. 94 (2), pp. 583-606, 1980.

[20] M. C. Zhang, J. S. Duan, Z. Y. Li, et al. Impact of Climate Warming on Crop Growth and Climate Productivity in Plain Area of the Loess Plateau, Resour. Sci. Chin, vol. 28, pp. 46-50, 2006.

[21] L. Zhou, H. J. Wang, H. W. Zhu. Simulation study on the impact of climate warming on production of winter wheat in Huang-Huai-Hai Plain of China. J. PLA Univ. Sci. Tech. China, vol. 4, pp. 76-82, 2003.

[22] K. Kristensen, K. Schelde, J. E. Olesen. Winter wheat yield response to climate variability in Denmark. Journal of Agriculture Science, vol. 149 (1), pp. 33-47, 2011. 